\title{
USING ENERGY EFFICIENT TEMPERATURE SENSOR FOR AUTOMATIC CONTROL OF THE HEATING AND COOLING SYSTEM IN THE HOME
}

\author{
P. Oshevire ${ }^{1, *}$, D. Okene ${ }^{2}$ and E. Okhueleigbe ${ }^{3}$ \\ 1, 2, 3 Dept of Electrical/Electronic Engr. Fed. Univ. of Petroleum Resources EFfurun, Delta State, NiGERIA \\ E-mail addresses:1ask4pat2001@yahoo.com, 2 okene.david@fupre.edu.ng, \\ 3 okhueleigbe.emmanuel@fupre.edu.ng
}

\begin{abstract}
With the development of modern technology, Smart Living is gradually changing people's life and thus providing a necessary technology to create convenience, intelligence and controllability. In this paper, a new Smart Living system is introduced for the Automatic Control of Heating and Cooling System in the Home. The system is designed to assist and provide support in order to fulfill some of the needs of elderly and disabled in the home as the elderly and the disabled are often in dire need of controlling their home environment. The main control system employed is a temperature sensor LM35 which serves as input signal to the central processing unit, which is the microcontroller whose function is for the overall control of the system. The output unit which consists of the relays which power on and off the 60 Watts bulbs (Heating system) and the fan (Cooling system), and an LCD (Liquid Crystal Display) which help to make the results of the test visible. The results of the test showed that the system automatically switched on and off two 60watt light bulbs and a 0.14 Amps fan at the preset temperature value (below $25^{\circ} \mathrm{C}$ and above $30^{\circ} \mathrm{C}$ ) through the LM35 temperature sensor.
\end{abstract}

Keywords. Smart Living, Temperature Sensor, Heating system, cooling system.

\section{INTRODUCTION}

\subsection{Background Study}

With advancement of technology things are becoming simpler and easier for us therefore automation plays an increasingly important role in the world economy and in daily experience this is why automatic systems are being preferred over manual system [1]. Therefore, home automation systems have been developed in recent years that make use of emerging technologies for development. It has become one of the upcoming fields that introduce many technologies for making the automatic control of home appliances easy [2]. In this project a method is devised to control the targeted home appliances through an independent temperature control system which responds to the ambient temperature conditions in the home. The proposed system is reliable, easy to setup, cost effective and overcome the downsides of existing systems. This system provides the variation in output corresponding to the change of surrounding temperature. It is more flexible, compatible and adjustable to any electrical and electronic devices [3]. The system is targeted for application in conventional homes for people with disabilities and the elderly. The design of this system will provide these people with added comfort in their own homes.

\section{DESIGN OVERVIEW}

Thermocouples, temperature dependent resistance elements (RTDs and thermostats) and semiconductor elements (diodes) are widely used to electrically measure temperature. Temperature measurement is not new in science and engineering field of study. Galileo invented a rudimentary thermometer capable of detecting temperature changes, and two hundred years later, See beck discovered the thermocouple. Given the long history of temperature measurement and its extensive use today [4], engineers over the years have continually designed and developed special devices called sensors which have been part of the advancement in temperature measurement device technology to enable automatic sensing, measurement 
and control of the temperature conditions in a particular area.

The idea behind this project involves the basic principle of switching networks in embedded systems, using miniaturized small signal, low frequency electronic devices such as the PIC16F877A microcontroller chip, transistor IC chips to control high frequency, large power electrical appliances in the home. The main control system as shown in figure1employs a temperature sensor to automatically activate connected home appliances at preset temperatures.

\section{DESIGN ANALYSIS}

The designed home automation system was analyzed with the associated theories and calculations, the system is comprised of PIC16F877A microcontroller,
LM35 temperature sensor enables automatic control of the appliances at preset temperature values, the three a. relays to which the electrical appliances are connected to, a ULN2003A relay driver for interfacing the relays with the microcontroller.

Figure2 below shows the full circuit with discrete components of this design. It is considered, here, as a temperature sensor LM35 which responses linearly with the temperature, the control circuit requires a $5 \mathrm{~V}$ DC supply.

\subsection{Design Analysis of the Power Supply Unit:}

The power supply section of this system comprises of a step-down transformer, a diode bridge rectifier, two a.c ripple filter capacitors and a voltage regulator. The block and circuit diagrams of the power supply unit are presented in figures 3 and 4 respectively.

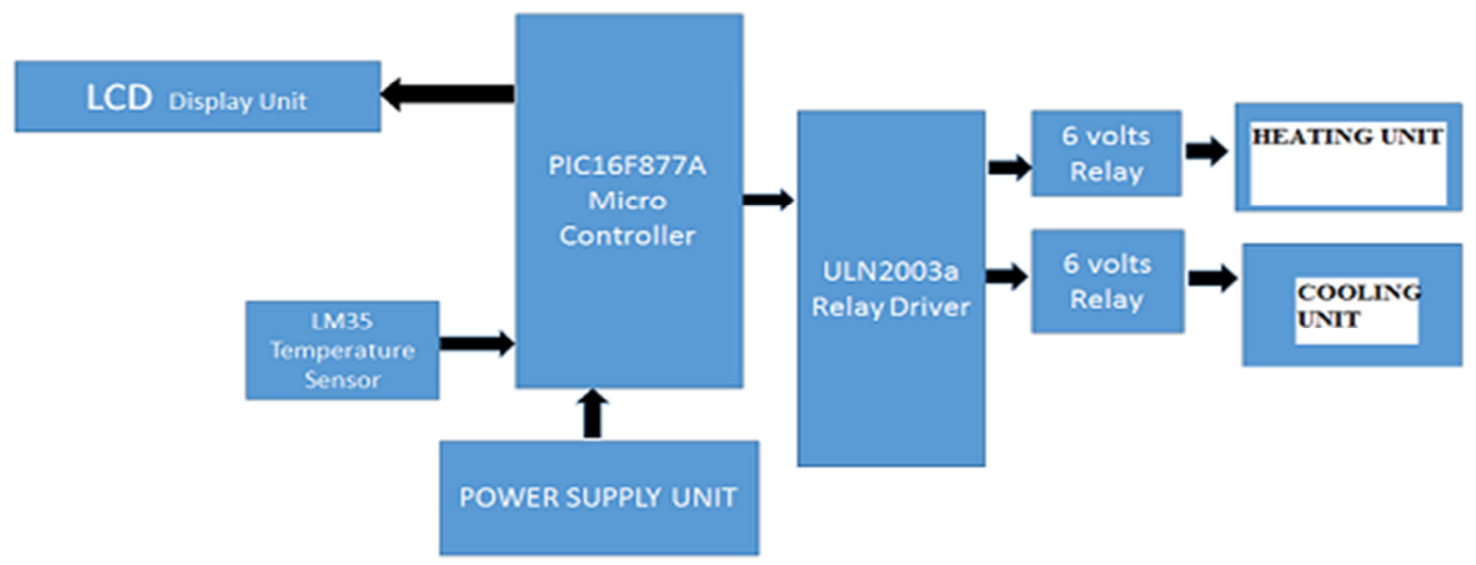

Figure 1: Block Diagram of Temperature Sensor Control System

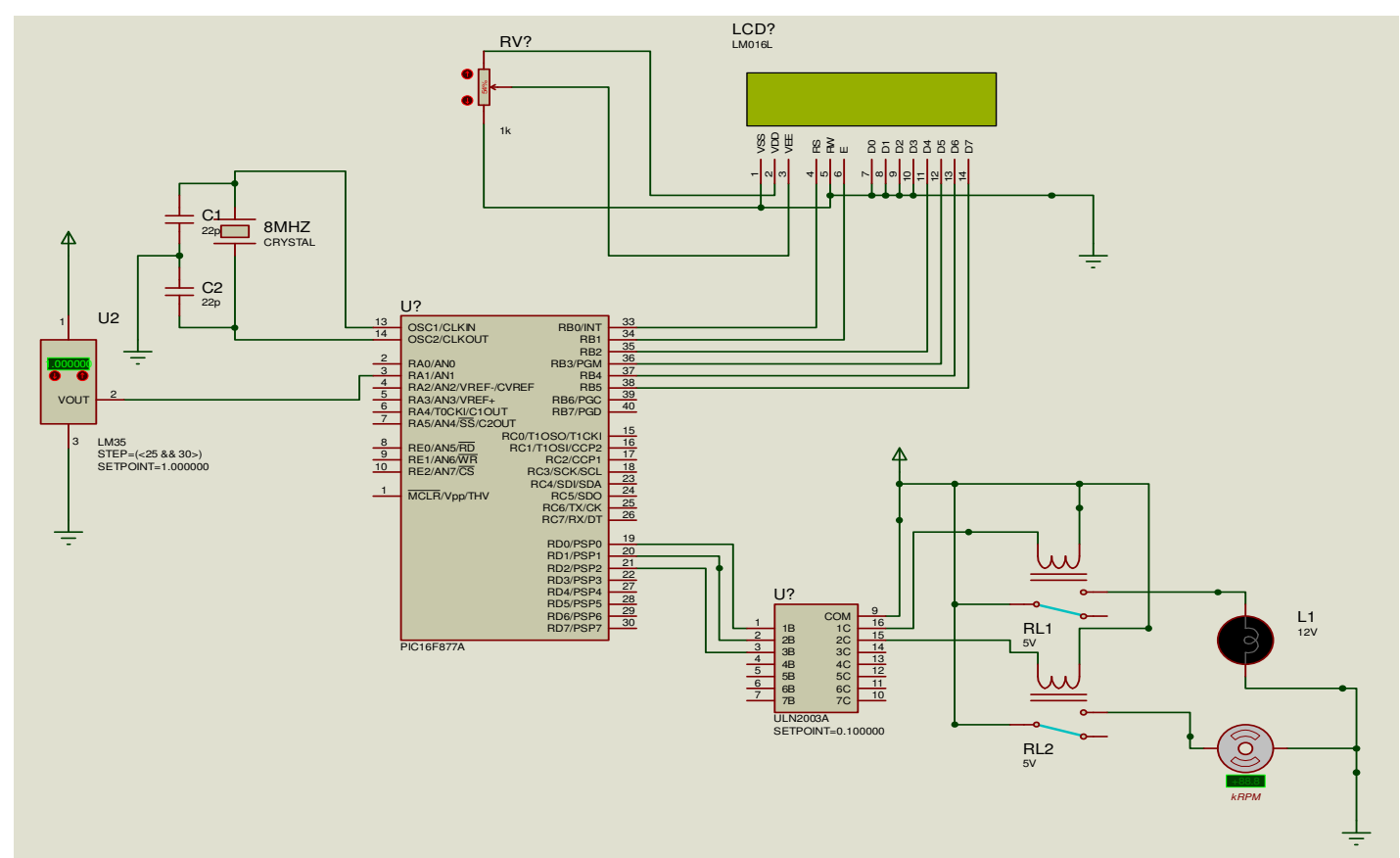

Figure 2.Complete Circuit Designed on Proteus 


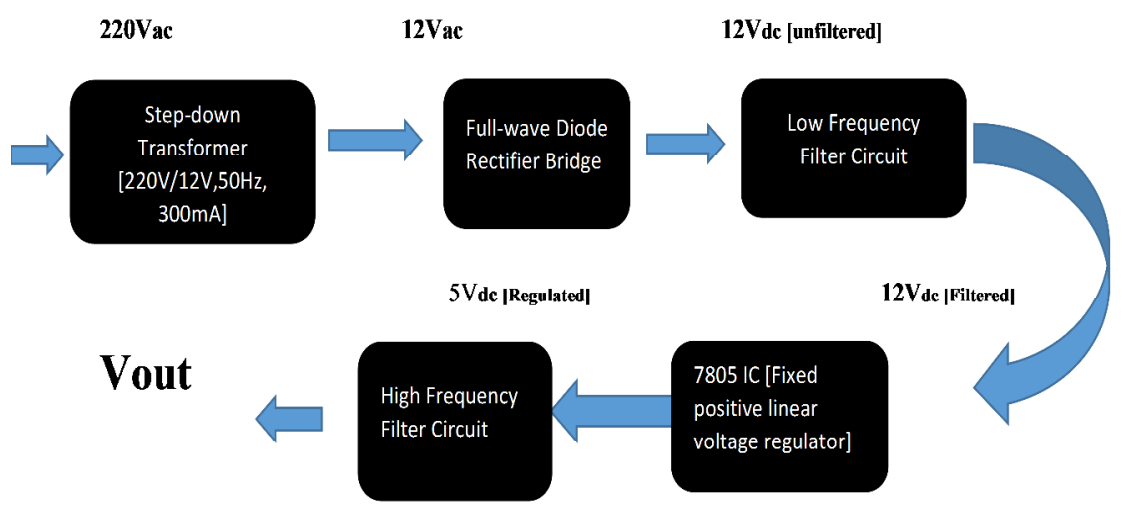

Figure 3: Block diagram of power supply unit

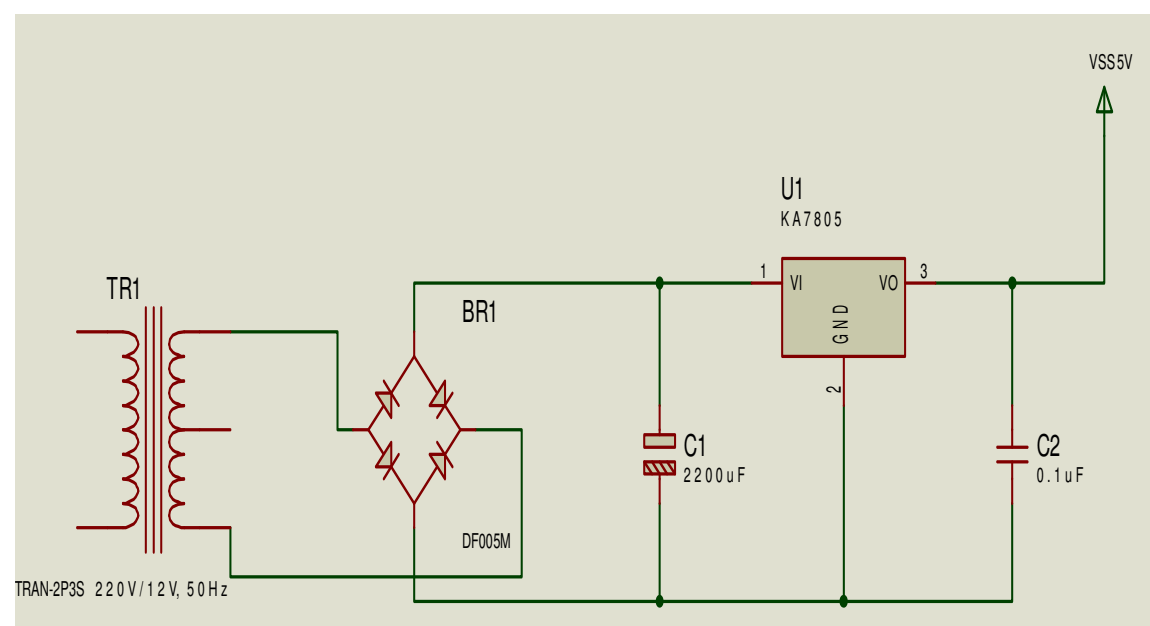

Figure 4: Power supply unit designed on Proteus 8

A step down transformer of $220 \mathrm{~V} / 12 \mathrm{~V}, 50 \mathrm{~Hz}, 300 \mathrm{~mA}$ was used for the design to power the controller and the relay section. It was chosen because the output voltage was safe and also enough to power the microcontroller section of the circuit which needed between $2.5 \mathrm{~V}-5.5 \mathrm{~V}$ for it to function properly.

The bridge rectifier diode used for the design has the following specification:

Forward voltage drop of $0.7 \mathrm{~V} \times 2=1.4 \mathrm{~V}$

Max current of the rectifier is $1 \mathrm{~A}$.

Since a voltage of $12 \mathrm{Vrms}$ AC is supplied by the transformer. The equivalent DC Voltage in R.M.S is given by:

Vrms $(D C)=$ Vrms (AC) - Forward Voltage Drop of Diode $=12 \mathrm{~V}-1.4 \mathrm{~V}=10.6 \mathrm{~V}$ DC

Therefore the peak Voltage $\mathrm{Vp}=$ Vrms (DC) $\times \sqrt{2}=$ 14.998V.

In this design, 15 Volts, an approximate value was used in subsequent calculations.

\subsubsection{Choice of Filtering Capacitor.}

In other to minimize ripple to at least $10 \%$, an electrolytic capacitor was used and its value was calculated using the formula: $C=\frac{5 \mathrm{I}_{\mathrm{o}}}{\mathrm{f} \mathrm{V}_{\mathrm{p}}}$ where $\mathrm{C}$ is the capacitance of the capacitor; Io is the output or load current of transformer; $f$ is the frequency and $V_{p}$ is the peak voltage.

For the transformer, output current $\mathrm{I}_{0}=300 \mathrm{~mA}$, frequency is $50 \mathrm{~Hz}$ and $V_{p}$ of $15 \mathrm{~V}$ was used. Therefore fixing in our values we have that $C=\frac{5 \times 300 \times 10^{-3}}{50 \times 15}=$ $2000 \mu \mathrm{F}$. Therefore the preferred market value of $2200 \mathrm{uF}$ capacitor was chosen for effective reduction of ripples in the signal.

After rectification of the mains supply, an unfiltered dc voltage with ripples is obtained. To reduce these ripples we use filters. It comprises of two filters low frequency ripple filter and high frequency ripple filter. To reduce low frequency ripples electrolytic capacitor was used.

The capacitors $\mathrm{C}_{1}$ and $\mathrm{C}_{2}$ act as filter circuit to reduce the effect of ac ripples from the power supply. The 
voltage rating of capacitor $\mathrm{C} 1$ must be double from incoming dc supply e.g. $2200 \mu \mathrm{F} / 25 \mathrm{~V}$ for the $12 \mathrm{~V}$ dc voltage. It blocks dc voltage and feeds it to the output terminal while passing the a.c. ripples to ground. The output filter capacitor is a $0.1 \mu \mathrm{F} / 50 \mathrm{~V}$ capacitor which helps to remove a.c ripples that might have escaped the first ripple filter [5].

The specifications of KA7805 IC voltage regulator from the National Semiconductor products datasheet was given as follows: regulated output voltage $5 \mathrm{~V}$, output current $1 \mathrm{~A}[6]$.

\subsection{Design Analysis of the Sensor Unit}

The sensor unit is made up of the LM35 temperature sensor and is analyzed in the next session.

\subsubsection{The LM35 Temperature Sensor Unit}

This unit as shown in Figure5 is made up of the LM35 analog temperature sensor IC.

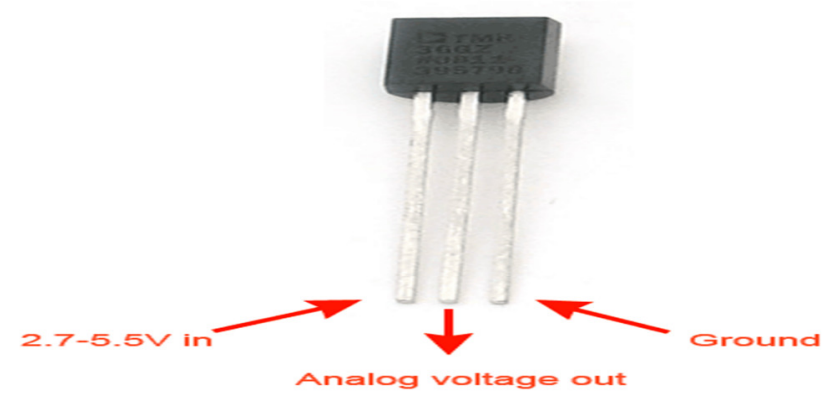

Figure 5: LM35 Temperature Sensor

It is a low cost and precision Integrated Circuit Temperature Sensor whose output voltage is linearly proportional to Centigrade temperature scale. Thus LM35 has an advantage over other temperature sensors calibrated in Kelvin as it does not require subtraction of large constant voltage to obtain the required Centigrade temperature. It doesn't requires any external calibration. It is produced by National Semiconductor and can operate over a full $-55^{\circ} \mathrm{C}$ to $+150{ }^{\circ} \mathrm{C}$ temperature range. Its output is linearly proportional to Centigrade Temperature Scale and it output changes by $10 \mathrm{mV}$ per ${ }^{\circ} \mathrm{C}$.

The LM35 temperature sensor has zero offset voltage, which means that the Output $=0 \mathrm{~V}$, at $0^{\circ} \mathrm{C}$. Thus for the maximum temperature value $\left(150^{\circ} \mathrm{C}\right)$, the maximum output voltage of the sensor would be $150 * 10 \mathrm{mV}=$ $1.5 \mathrm{~V}$. If the supply voltage $(5 \mathrm{~V})$ is used as the Vref+ for Analog to Digital Conversion (ADC) the resolution will be poor as the input voltage will only drive up to $1.5 \mathrm{~V}$ and the power supply voltage variations may affect ADC output. So it is better to use a stable low voltage above 1.5 as Vref+.

\subsubsection{Converting ADC Reading to Celsius degrees}

Knowing that the ADC has a step size of $4.883 \mathrm{mV}$, converting our digital reading back to voltage is simply done by multiplying the digital reading by the step size: Vin (in Volts) = Digital Reading * 0.004883

Now, knowing our sensor's sensitivity is $10 \mathrm{mV} / \mathrm{C}$, converting this voltage to Celsius is simply done by dividing the input voltage by 0.01 ,

Therefore temperature $(\mathrm{C})=$ Vin $/ 0.01=$ Digital Reading x 0.4883 [7].

\subsection{Design Analysis of the Processing Unit 3.3.1 PIC16f877a Microcontroller}

A PICF16f877A microcontroller is employed in this design and since it has all the unique interface for both input and the output control, making it possible for a reduction in the number of discrete electronic components. This is an integrated circuit which was programmed with a TopWin2008 flash programmer to receive input signals and relating it to other interfaced sub-unit attached to it for their corresponding signal generation.

It receives inputs from the input peripheral devices and processes these signals with respect to how it is programmed, and performs a set of operations accordingly. The PIC16F877A microcontroller is a 40 pin RISC IC. This PIC microcontroller differs from other PICs because of the features like 10 bit, 8 channels inbuilt ADC, inbuilt PWM, and one 8 bit USART.

The inbuilt Analog to Digital Converter (ADC) eliminates the use of external ADCs like ADC2803 and its family. PIC ADC module has software selectable high and low voltage reference input to some combination of VDD, VSS, RA2 and RA3.

In this project we converted the analog input to channel 1 to 10 bit digital number with low voltage reference (Vref-) $0 \mathrm{v}$ and high voltage reference (Vref+) 5V. The output is read and shown on the LCD and also determines the microcontroller section of the appropriate relay to switch. The Vref and Vref + can be changed by configuring the ADCON1 register.

$0 \mathrm{v}=0000000000$

$5 \mathrm{v}=1111111111$

Resolution $=\frac{(\text { Vref }+- \text { Vref- })}{(1024-1)} \quad$ (as it is a 10 bit $\mathrm{ADC})=\frac{5}{1023} \quad=4.887 \mathrm{mV}$. 


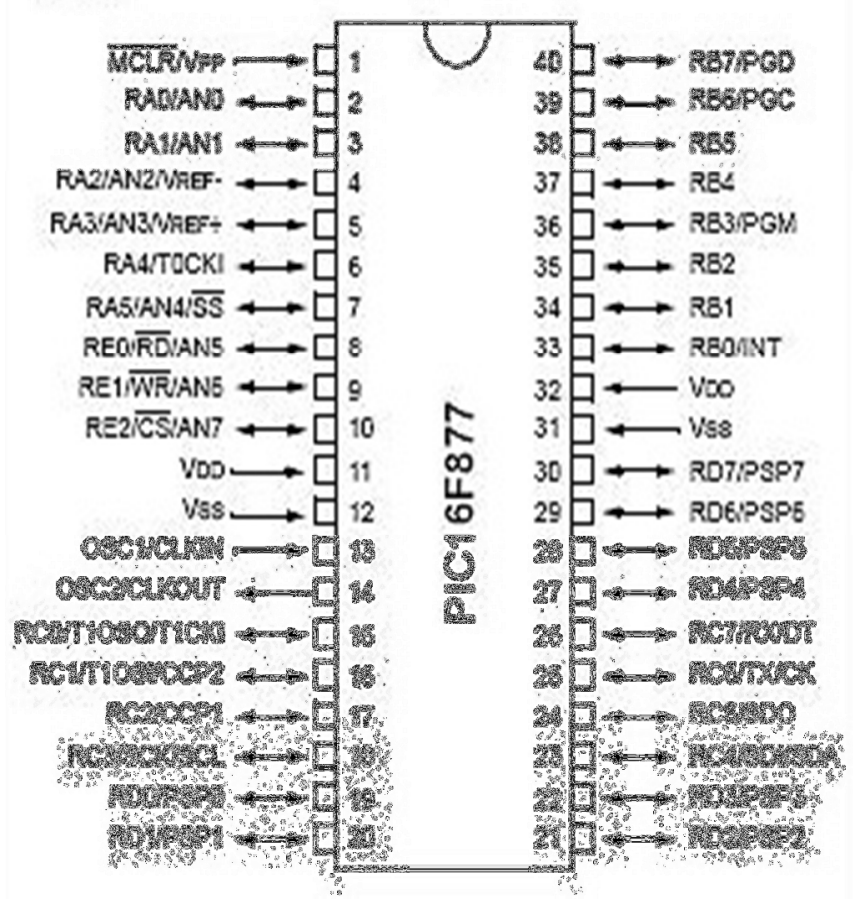

Figure 6: Microcontroller show input/output pins of PIC16F877A

Thus it means that for a change in $4.887 \mathrm{mV}$, the binary output changes by 1 .

With four (4) I/O ports, it is suitable for this project with a whole lot of reserved pins in case the projects gets more complex and there is need to use the redundant I/O pins [8].

\subsubsection{Programming of the PIC16f877a Microcontroller Chip}

The MikroElectronika micro-C PRO for PIC v6.0.0 (Figure 6) was used to write and compile the programming codes for the PIC16F877A microcontroller. The programming language used was Micro-C programming language for PIC. Top Win 2008 Programmer was used to program the microcontroller chip. This is shown in Figure7, while figure8 represents the source codes.

\section{IMPLEMENTATION}

The construction of this project was done on a Vero board. Vero board is also called a strip board. It is a widely-used type of electronics prototyping board characterized by a 0.1 inch $(2.54 \mathrm{~mm})$ regular (rectangular) grid of holes, the type used has parallel strips of copper coating along the entire length of the board in one direction. When using the Vero board some of the parallel copper linings were stripped off to create a break around the holes, this helped to

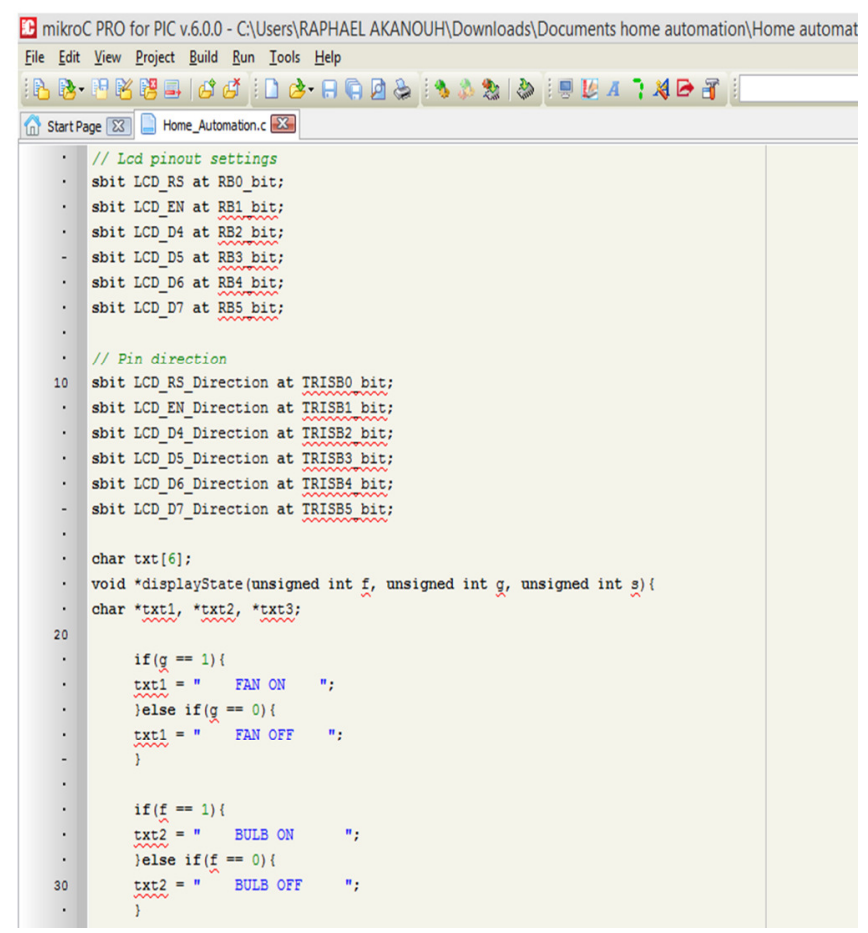

Figure 7: Micro C PRO for PIC Compiler

prevent continuous electrical lines where it is not needed.

\subsection{Implementation of the Processing Unit}

Figure9 shows the processing unit. This is the most essential section of the system as it is the component in charge of controlling the functionality of the entire home automation system. A 40-pin series microcontroller socket was mounted and soldered on the Vero board inside the socket the two 10pf ceramic capacitors were soldered, then the PIC16F877A microcontroller was mounted on the socket. The $8 \mathrm{MHz}$ crystal was mounted and soldered in between the two terminals of the capacitors beside the microcontroller.

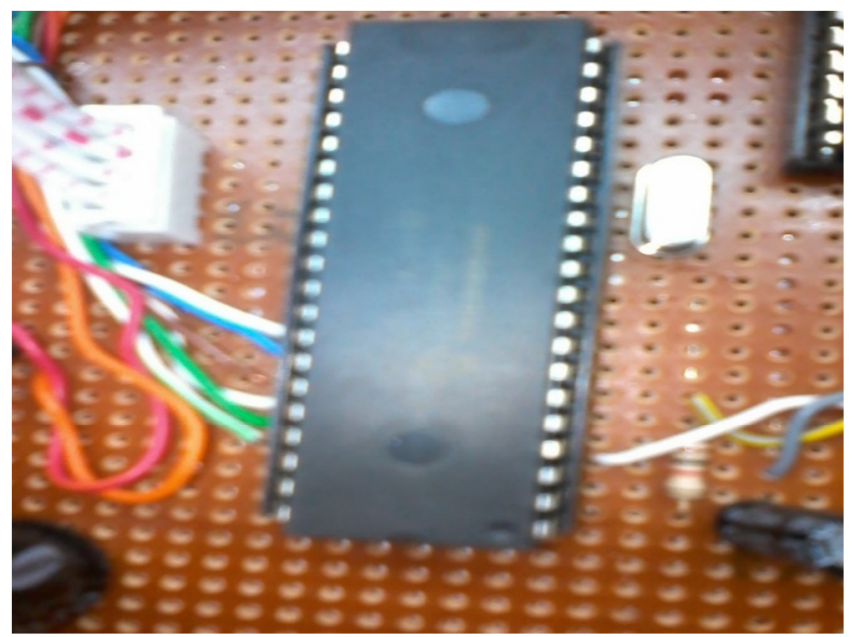

Figure 9: Photo view of the PIC16F877A mounted on connector socket with external $8 M H z$ crystal

Vol. 34 No. 4, October 2015 


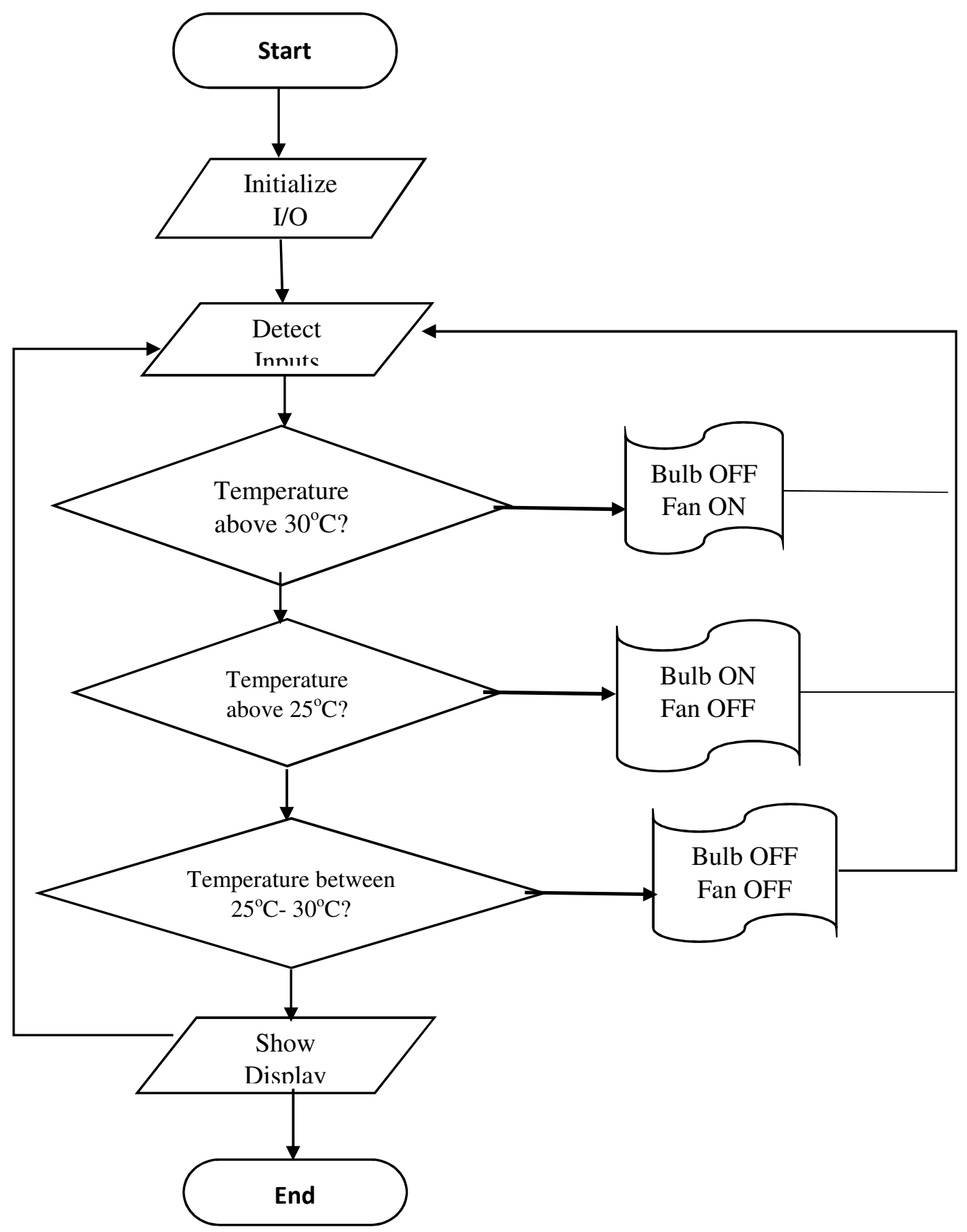

Figure 8. Flow Chart Programming of the Home Automation System

\subsection{Implementation of the Display Unit}

The hardware set up of the LCD display module interface with the PIC16F877A microcontroller was achieved by connecting the following pins of the LCD; Pin 1 was solder to a jumper wire connected to ground and pin 2 using a jumper wire was connected to the +5 volts supply (figure 10 ).

\subsection{Implementation of the Sensor Unit}

LM35 The LM35 was first soldered on a small piece of Vero board, one end of jumper wires was soldered to the terminals of the temperature sensor on the Vero board then the other end was soldered to the analog pins of port $\mathrm{A}$ of the microcontroller to complete the hardware connection.

For the software part of implementation of the temperature sensor LM35 the A/D Port Configuration Control bits from the PIC16F877A manufacturer's data was used to configure the analog pins AN0 to AN7 at port A of the microcontroller, this enabled the smooth interface control of the LM35 sensor on the microcontroller with the written program codes. 


\subsection{Implementation of the Power Supply Unit}

The following components were used to set up the power supply unit as shown in figure11;

-220/12V 300mA 50Hz Step-down transformer

- First filter component $2200 \mu \mathrm{F}, 25 \mathrm{~V}$ electrolytic capacitor, second filter component

\section{...0.1uf/50vcapacitor}

- Diode Bridge rectifier, and

- $5 \mathrm{~V}$ voltage regulator

The primary side of the transformer was connected to a $220 \mathrm{~V}$ AC mains while the $12 \mathrm{~V}$ secondary side was connected to the alternating voltage input pins of the bridge rectifier.

The DC output of the bridge rectifier was passed through the first a.c. ripple filter component $2200 \mu \mathrm{F}$,
$25 \mathrm{~V}$ electrolytic capacitor, and then sent to the LM7805 5V voltage regulator which supplies the constant $5 \mathrm{~V}$ voltage supply needed by the PIC16F877A before passing it through the second filter component $0.1 \mu$ capacitor.

The soldering process was carried out using a lead and a $6 \mathrm{w}$ soldering iron. This was done by joining terminals together before soldering. And after soldering each unit, test was carried out using a multimeter to ensure good contact. A patrax box was used for the enclosure of the project Patrax is an electrical installation box used for housing electrical/electronic components. It is made of plastic material, $50 \times 20 \mathrm{~mm}$ rectangular shape with $10 \mathrm{~mm}$ thickness. This box shown in Figure12 houses the control unit.

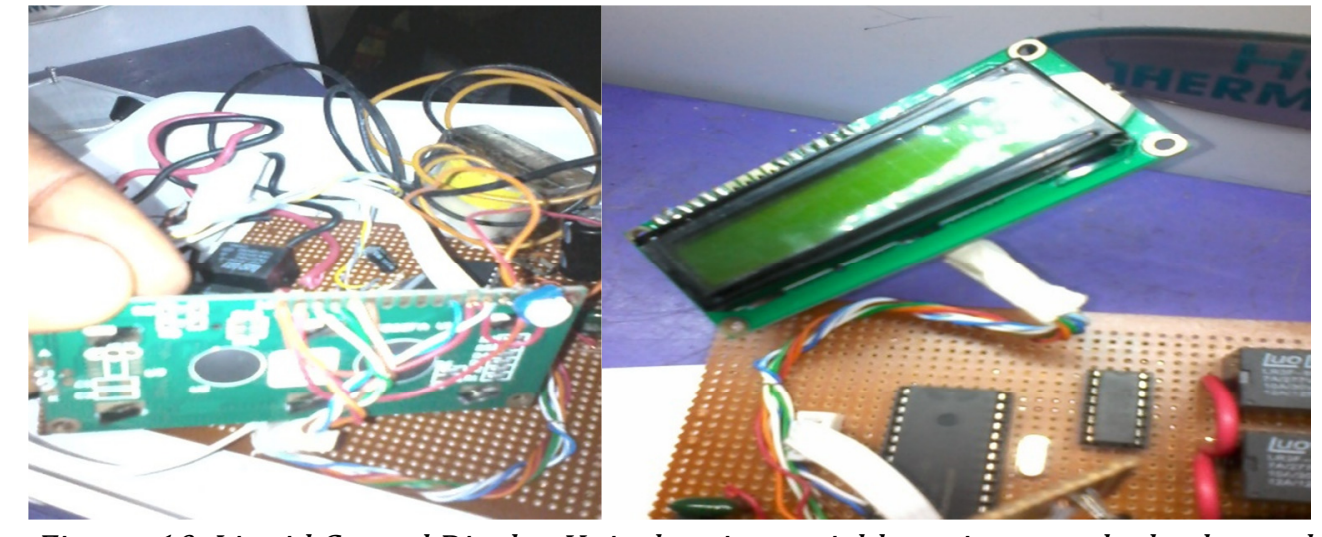

Figure: 10. Liquid Crystal Display Unit showing variable resistor on the back panel

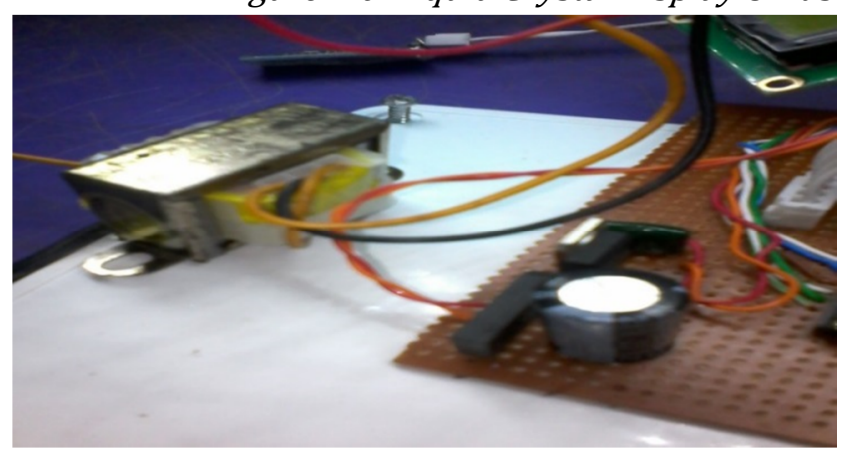

Figure: 11. Photo view of the Power Supply Unit of the Home Automation System

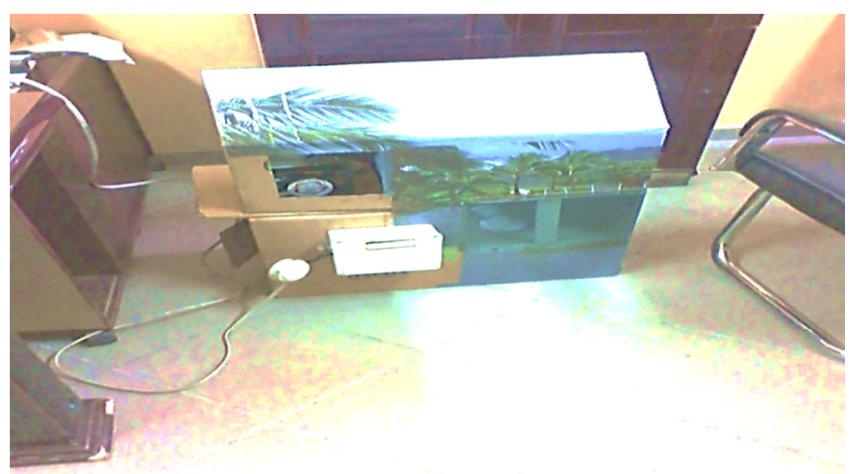

(Heating and Cooling Units in OFF state)

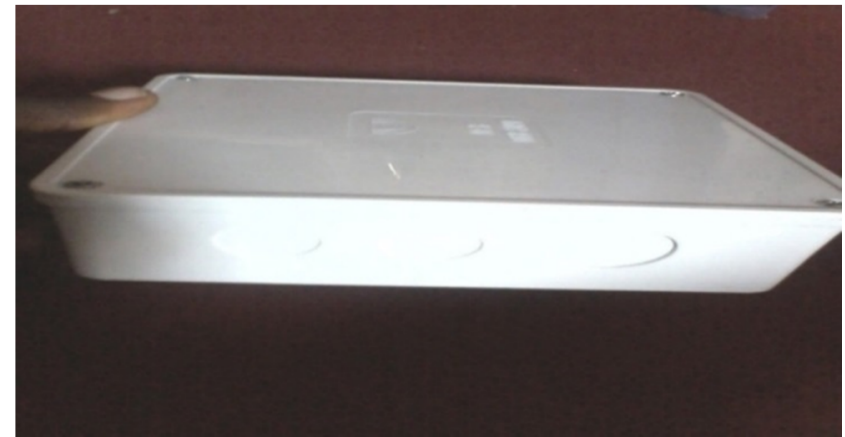

Figure 12: Photo view of Patrax box housing the entire control system

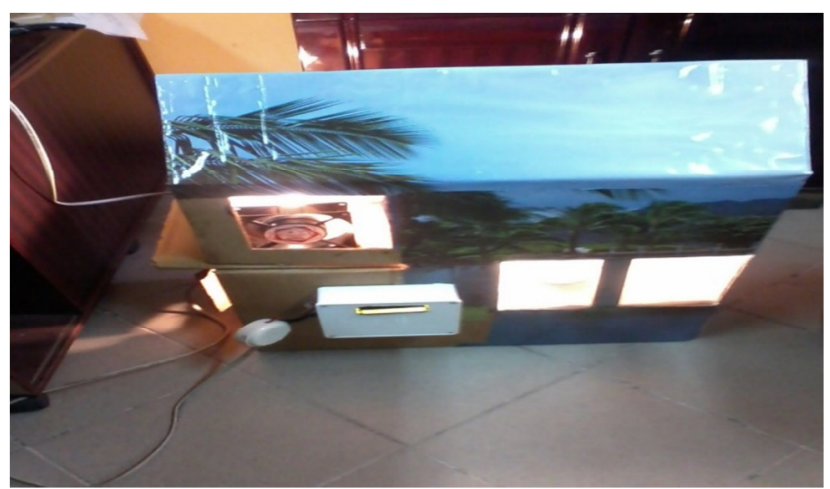

(Heating and Cooling Units in ON state)

Figure 13.Photo view of The Home Automation System House Model. 


\section{RESULTS}

The automatic temperature sensor control system was able to switch on and off a 60 watt light bulb and a 220volt, 0.14amp a.c fan through the LM35 temperature sensor at the preset temperature value, below $25^{\circ} \mathrm{C}$ and above $30^{\circ} \mathrm{C}$. At temperatures between $25^{\circ} \mathrm{C}$ and $30^{\circ} \mathrm{C}$ the connected appliances were not activated.

\section{CONCLUSION}

The designed automatic temperature sensor control system was tested a number of times and certified to control, the air conditioning system, fans, heating system, (this is as long as the maximum power and current rating of the appliance does not exceed that of the used relay).

It is evident from this work that the system can be made cheaply from low-cost locally available components and better still, the components required are so small and few that they can be packaged into a small inconspicuous container.

\section{ACKNOWLEDGEMENT}

The authors acknowledge the help of Akanuoh Raphael Chojakeme in the construction of the prototype of the project used in this paper.

\section{REFERENCES}

[1] C.H.Okorafor.(2013), "Construction Of A Gsm Based Home Automation Using AVR", Bachelor of
Engineering (B.Eng) In Electrical And Electronic Engineering, Faculty of Engineering Caritas University Amorji-Nike, Enugu.

[2] V. S. Narayanan and S. Gayathri.(2013), M.E Embedded System Technology, Anna University, Coimbatore, India. 1 Volume III, Special Issue.

[3] Md. M. Hoque and S. Alam, (2014), "A Temperature Based Automatic Power Controller for Electrical Devices", International Journal of Advanced Science and Technology Vol.63, pp.1-8 http://dx.doi.org/10.14257/ijast.2014.63.01\, retrieved September 2014.

[4] M. Mayes. (January 2015), "Journal of Analog Innovation", LTjournal-V24N4-00-df-LTC2983MichaelMayes.pdf.Fromhttp://www.linear.com, retrieved September 2014.

[5] B. L. Theraja and A.K. Theraja. (2005), Chapter 56 Regulated Power Supply. A Textbook of Electrical Technology, pages 2175-2177.

[6] National Semiconductor.(1995), "KA7805 Voltage regulator". National Semiconductor Corporation, retrieved September 2014.

[7] Texas Instrument.(SNIS159D - August 1999 Revised October 2013), LM35 Datasheet. From www.alldatasheet.com/datsheetpdf/pdf/517588/TI1/LM35.html, retrieved September 2014.

[8] Microchip.(2003), Microchip Technology Inc. "PIC 16F877a Datasheet". From

http://www.microchip.com/downloads/en/DeviceDoc 39582b.pdf, retrieved September 2014 